\title{
Pesquisa em ensino de biologia: características da produção acadêmica do Programa de Pós-Graduação em Ensino de Ciências da Universidade Federal Rural de Pernambuco, Brasil
}

\author{
Biology education research: Academic production \\ characteristics of the graduate program in science education \\ at the Federal Rural University of Pernambuco, Brazil
}

Michelle Garcia da Silva ${ }^{1}$. Edenia Maria Ribeiro do Amaral $^{2}$

\begin{abstract}
Resumo: Este artigo apresenta um estudo referente à pesquisa em ensino de Biologia, pautado na descrição, análise e caracterização das dissertações defendidas no Programa de Pós-Graduação em Ensino de Ciências (PPGEC), da Universidade Federal Rural de Pernambuco (UFRPE). Para tal, foram analisadas 41 dissertações defendidas no período de 2003 a 2009, a partir de descritores propostos pelo Centro de Documentação em Ensino de Ciências (CEDOC), da Faculdade de Educação da Universidade Estadual de Campinas (UNICAMP): ano de defesa, autor e orientadores, nível de ensino, foco temático e gênero do trabalho acadêmico. Os resultados mostraram que a pesquisa em Ensino de Biologia do PPGEC/ UFRPE apresenta características comuns à pesquisa nessa área em âmbito nacional, como o predomínio de problemáticas que envolvem a Educação Básica. E, também, características singulares que refletem o processo de implantação e consolidação do curso de mestrado do PPGEC/UFRPE.
\end{abstract}

Palavras-chave: Pesquisa em ensino de biologia. Produção acadêmica. Dissertação de mestrado.

\begin{abstract}
This paper presents a study related to research in teaching of Biology, based on the description, analysis and characterization of dissertations in the Graduate Program in Science Teaching (PPGEC), University Federal Rural of Pernambuco (UFRPE). For this, 41 dissertations were analyzed in the period 2003-2009, taking into account descriptors proposed by Centro de Documentação em Ensino de Ciências (CEDOC) from Universidade Estadual de Campinas (UNICAMP): the year of defense, author and supervisors, educational level, thematic focus and type of academic work. The results showed that the research in teaching of Biology in PPGEC/UFRPE presents common characteristics in this area at the national level, for instance, within the prevalence of research themes involving basic education. Also there are specific characteristics for academic production that reflect the process of implementation and consolidation of the Master course in the PPGEC/UFRPE.
\end{abstract}

Keywords: Biology Education Research. Academic production. Master dissertation.

\footnotetext{
${ }^{1}$ Universidade Estadual da Paraíba, Rua Bezerra Luiza Mota, 950, ap. 202-E, Catolé, CEP 58410-410, Campina Grande, PB, Brasil. E-mail: <michellegarcia.silva@gmail.com>

${ }^{2}$ Departamento de Química, Universidade Federal Rural de Pernambuco (UFRPE), Recife, PE, Brasil.
} 


\section{Introdução}

A pesquisa em ensino de Biologia vem sendo objeto de vários estudos que se dedicam a analisar a produção acadêmica nesta área (SLONGO, 2004; SLONGO; DELIZOICOV, 2006; TEIXEIRA, 2008; TEIXEIRA; MEGID NETO, 2011; TEIXEIRA; SANTOS, 2010). Estes estudos compartilham o objetivo de descrever, analisar e caracterizar as dissertações e teses sobre o ensino de Biologia, a fim de aprofundar a compreensão e a caracterização da produção do conhecimento na área. O que se tornou necessário a partir do avanço do campo de pesquisa em Educação e Ensino de Ciências, campo ao qual a pesquisa em ensino de Biologia está vinculada.

Nos últimos quarenta anos, o campo de pesquisa concernente ao Ensino de Ciências avançou significativamente (TEIXEIRA; MEGID NETO, 2011). Vários fatores contribuíram para tal avanço, dentre eles, a criação da Área de Ensino de Ciências e Matemática, em 2000, junto à Coordenação de Aperfeiçoamento de Pessoal de Nível Superior (CAPES). Com a criação da área, houve uma expansão considerável no número de programas de Pós-Graduação (PG) direcionados ao Ensino de Ciências. Nesse contexto, surgiram, em instituições do Norte, Nordeste e Centro-Oeste, alguns programas de PG na área (TEIXEIRA; MEGID NETO, 2006). Um deles foi o Programa de Pós-Graduação em Ensino de Ciências (PPGEC) da Universidade Federal Rural de Pernambuco (UFRPE), aprovado pela CAPES em 2001, para o nível de mestrado. Em 2009, foi aprovado o curso de Doutorado do programa, que, a essa época, já acumulava quase dez anos em pesquisas desenvolvidas no campo relativo ao Ensino de Ciências.

Nardi (2007) afirma que os programas instituídos em um período mais recente, nos quais incluímos o PPGEC/UFRPE, merecem estudos de revisão particulares, visando reunir uma produção aparentemente dispersa, mas que, em seu conjunto, é bastante significativa para a educação científica brasileira. Segundo o autor, entender as características da produção acadêmica desenvolvida nos programas de pós-graduação em Ensino de Ciências é importante para a área, tanto para consolidar as discussões nacionais do estado da arte da pesquisa em Ensino de Ciências, quanto para entender as necessidades educacionais regionais que essas pesquisas sinalizam em seus resultados.

Assim, os estudos realizados a partir da análise de dissertações e teses se justificam no sentido de subsidiarem novas possibilidades de pesquisas, apontarem lacunas e identificarem limites revelados no conjunto da produção em análise (MEGID NETO, 2007). Além de socializarem, compatibilizarem, caracterizarem e integrarem os conhecimentos gerados pelas pesquisas, os tornando, desta forma, agentes efetivos de mudança na educação em Ciências no país, tanto regional quanto nacionalmente.

Considerando a produção acadêmica em Ensino de Biologia, é revelado, por todas as pesquisas que investigam essa produção em nível nacional, que a mesma está concentrada no eixo Sul-Sudeste. No entanto, a criação de programas de Pós-Graduação nas regiões Norte, Nordeste e Centro-Oeste vem contribuindo, significativamente, para alterar essa distribuição, promovendo o desenvolvimento de pesquisas mais compatíveis com os interesses e necessidades regionais. Assim, desenvolvemos este trabalho partindo do seguinte questionamento: como 
se caracteriza a pesquisa sobre Ensino de Biologia no Programa de Pós-Graduação em Ensino de Ciências da Universidade Federal Rural de Pernambuco, quando consideradas as dissertações de mestrado produzidas nessa área?

$\mathrm{Na}$ busca de encontrar elementos que tornassem possível responder ao questionamento exposto, foram feitas as escolhas metodológicas apresentadas no item a seguir.

\section{Delineamento metodológico}

Esta pesquisa se caracteriza como um estudo de revisão bibliográfica que, segundo Megid Neto (1999), é centrado na identificação, sistematização e avaliação da produção de pesquisas em determinada área do conhecimento ou campo de pesquisa. Segundo o autor, aos estudos de revisão bibliográfica, cabem os seguintes procedimentos: (1) a identificação de trabalhos produzidos na área - tais como dissertações, teses, artigos publicados em periódicos, relatórios de pesquisa, trabalhos publicados em atas de eventos científicos, entre outros; (2) a seleção e classificação dos documentos segundo critérios e categorias estabelecidas em conformidade com os interesses e objetivos do pesquisador; (3) a descrição e análise das características e das tendências do material; e (4) a avaliação dos seus principais resultados, contribuições e lacunas.

O presente estudo pretende contribuir com a análise da pesquisa em Ensino de Biologia desenvolvida em um dos primeiros programas de Pós-Graduação em Ensino de Ciências do Nordeste, o PPGEC/UFRPE. E representa um recorte de um projeto maior desenvolvido no âmbito do programa Observatório da Educação.

O Observatório da Educação é uma proposta da Coordenação de Aperfeiçoamento de Pessoal de Nível Superior (CAPES), do Instituto Nacional de Estudos e Pesquisas Educacionais Anísio Teixeira (INEP) e da Secretaria de Educação Continuada, Alfabetização e Diversidade (SECAD), com especial interesse em estudos relacionados com a docência e a formação dos profissionais da Educação Básica. No sentido de contribuir com essa reflexão, foram analisadas 41 dissertações em Ensino de Biologia, defendidas no PPGEC/UFRPE no período de 2003 a 2009. A escolha desse período está associada ao ano em que o PPGEC/ UFRPE foi reconhecido pela CAPES, 2001, com dissertações defendidas a partir de 2003; e ao ingresso da autora deste trabalho no programa em 2009, ano que se tornou um limite viável para a análise das dissertações em suas versões finais.

Para a constituição da amostra, inicialmente, foram identificadas as dissertações defendidas entre 2003 e 2009. Após essa identificação, as dissertações foram classificadas de acordo com a área disciplinar à qual estava vinculada e, finalmente, foram selecionadas aquelas dissertações relativas ao ensino de Biologia ou áreas afins.

Os primeiros dados foram construídos a partir de uma leitura dos resumos das dissertações, na qual buscamos identificar se os mesmos apresentavam elementos básicos do trabalho, tais como: objetivo, fundamentação teórica, metodologia, principais resultados e conclusões. Posteriormente, foi realizada uma leitura integral dos documentos e elaborada uma Ficha de Classificação Individual, adaptada com base no trabalho de Teixeira (2008). Esta ficha contém os 
resultados das análises dos descritores selecionados para este estudo, e que serão apresentados a seguir, tomando por base, sobretudo, os trabalhos realizados no Centro de Documentação em Ensino de Ciências (CEDOC) ${ }^{3}$.

Os descritores utilizados neste estudo:

a) Ano de defesa: parte-se da identificação do ano de defesa da dissertação (MEGID NETO, 1998), buscando caracterizar o desenvolvimento da produção acadêmica ao longo do tempo, o que pode contribuir para compreender a sua evolução histórica, em termos quantitativos - podendo ser verificados momentos de crescimento, estacionamento, estrangulamento ou decréscimo, quando houver;

b) Autor e orientadores: com este descritor, pode-se traçar um perfil de formação para autores e orientadores, levando em consideração a formação inicial dos autores e a área acadêmica de origem dos orientadores (MEGID NETO, 1998). No nosso caso, fomos além, e buscamos, também, especificar a área da última formação dos orientadores;

c) Nível de ensino: para este descritor, o objetivo é identificar o nível escolar foco da problemática da pesquisa. Assim, as pesquisas podem estar direcionadas para um nível escolar específico, para mais de um nível escolar - sendo classificadas, então, em todos os níveis em foco; para nenhum nível escolar específico, quando se tratar de uma abordagem mais geral no que se refere ao nível de ensino; ou, ainda, para a "educação não formal". Assim, segundo Megid Neto (1998), os indicadores para este descritor são os seguintes:

. Ensino Infantil;

. Ensino Fundamental;

- Ensino Fundamental I;

- Ensino Fundamental II;

- Ensino Médio;

- Ensino Superior;

- Geral: a pesquisa não se refere a um nível de ensino específico;

- Outros: a pesquisa trata de processos não escolarizados ou não formais de ensino.

d) Foco temático: com este descritor, busca-se identificar os problemas investigados nas teses e dissertações (MEGID NETO, 1998). Os indicadores para este descritor, segundo o referido autor, são relacionados abaixo:

- Currículo e programa;

- Formação de professores;

- Conteúdo-Método;

- Recursos didáticos;

- Formação de conceitos;

- Características do professor;

- Características do aluno;

${ }^{3}$ O Centro de Documentação em Ensino de Ciências (CEDOC) é coordenado pelo FORMAR-Ciências (Grupo de Estudos e Pesquisas em Formação de Professores da Área de Ciências), da Faculdade de Educação da UNICAMP. Desenvolve estudos e pesquisas sobre a produção acadêmica e didática na área de Educação em Ciências - Ciências Naturais, Biologia, Física, Química, Geociências, Saúde e Educação Ambiental, nos diversos níveis escolares. Disponível em: <http://www.fe.unicamp.br/cedoc/>. Acesso em: 28 nov. 2014. 
- Organização da escola;

- Organização da instituição/programa de ensino não escolar;

- Políticas públicas;

- História do Ensino de Ciências;

- História da Ciência;

- Filosofia da Ciência;

- Outro: corresponde a estudos que não se enquadram em nenhum outro foco.

e) Gênero do trabalho acadêmico: neste caso, buscam-se caracterizar os documentos investigados quanto ao tipo ou forma do texto acadêmico. Assim, os indicadores deste descritor, segundo Soares e Maciel (2000), são:

- Ensaio;

- Relato de experiência;

- Pesquisa;

- Pesquisa histórica;

- Pesquisa descritivo-explicativa;

$\checkmark$ Survey;

$\checkmark \quad$ Estudo de caso;

$\checkmark \quad$ Estudo comparativo;

$\checkmark \quad$ Análise de documento;

$\checkmark \quad$ Estudo longitudinal;

$\checkmark \quad$ Estudo transversal;

- Pesquisa experimental;

- Mais de um tipo de pesquisa (mais de um gênero é identificado).

\section{Resultados e discussão}

Após a leitura dos documentos, a análise foi feita tendo como orientação cada um dos descritores propostos pelo CEDOC, e, dessa forma, apresentaremos os principais resultados relativos a estes descritores.

\section{a) Ano de defesa}

Foi encontrada uma média de cinco dissertações defendidas por ano no PPGEC/ UFRPE. Estas dissertações se distribuíram de forma contínua, de maneira que houve defesas durante todos os anos que compõem o intervalo de tempo investigado (2003-2009). Além de contínua, a distribuição dos trabalhos se apresentou de forma irregular, em termos quantitativos. Tal irregularidade é revelada pela oscilação no número de trabalhos defendidos a cada ano, número este que ora cresce, ora diminui, ao longo do período analisado. A evolução desta produção pode ser visualizada no Gráfico 1.

As características anteriormente pontuadas - continuidade e irregularidade na distribuição dos trabalhos defendidos no período estimado - estão associadas, no caso do PPGEC/ UFRPE, ao processo seletivo realizado pelo programa. Nesta seleção, procura-se fazer uma distribuição equitativa de candidatos por área de interesse (Biologia, Química, Física, Matemática e áreas afins). No entanto, áreas como a Biologia e a Matemática apresentam maior número de inscritos, e, consequentemente, mais candidatos são aprovados para estas áreas. 
Gráfico 1. Dissertações relacionadas ao Ensino de Biologia defendidas no PPGEC/UFRPE no período de 2003 a 2009

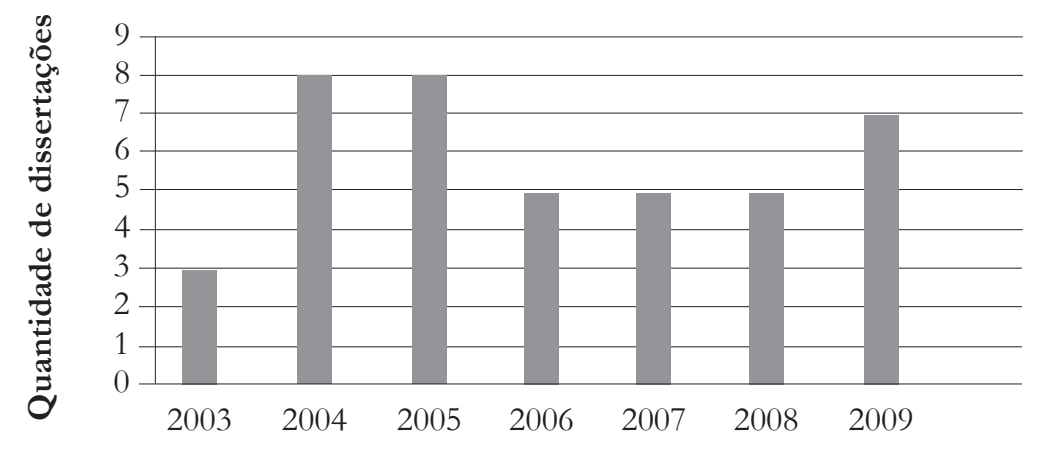

Ano de defesa

Fonte: elaborado pelas autoras.

Assim, torna-se contínua a defesa de dissertações concernentes ao ensino de Biologia, e irregular à medida que o número de candidatos aprovados com interesse em pesquisar sobre o Ensino de Biologia oscila a cada seleção. A irregularidade na destruição da produção acadêmica é, também, uma característica da pesquisa em Ensino de Biologia no âmbito nacional (TEIXEIRA, 2008).

Ainda em termos quantitativos, foi possível perceber que a produção sobre o Ensino de Biologia, no PPGEC/UFRPE, elevou em quase quatro vezes a produção do estado de Pernambuco na área, considerando resultados de estudos anteriores ao nosso, como o de Teixeira (2008). Segundo o autor, o estado de Pernambuco contabilizava dez dissertações de mestrado relacionadas ao Ensino de Biologia, em 33 anos de pesquisa na área (1972-2004), das quais, cinco foram desenvolvidas na Universidade Federal Rural de Pernambuco no Programa de Pós-Graduação em Ensino das Ciências (TEIXEIRA, 2008).

Considerando as dissertações sobre o Ensino de Biologia defendidas no PPGEC/ UFRPE nos anos de 2003 e 2004, período comum entre o estudo desenvolvido por Teixeira (2008) e o nosso, verificamos que, além das quatro dissertações apontadas pelo autor, foram encontradas mais sete dissertações defendidas no PPGEC/UFRPE no referido período, o que contabilizou um crescimento de dez para 17 trabalhos da área, no estado. Acrescentando as produções realizadas nos cinco anos posteriores àqueles analisados por Teixeira (2008) [19722004], ou seja, no período entre 2005 a 2009, o PPGEC/UFRPE contribuiu com a defesa de 30 dissertações de mestrado relacionadas ao Ensino de Biologia, o que possibilitou um crescimento de 17 para 47 trabalhos na área no estado. A partir do exposto, é possível fazer duas considerações importantes: (1) é efetiva a contribuição do PPGEC/UFRPE para o crescimento da pesquisa voltada ao Ensino de Biologia no estado de Pernambuco; (2) é concreta a dificuldade de realizar um levantamento preciso das dissertações e teses defendidas no âmbito dos programas de pós-graduação em ensino de Ciências. 
A dificuldade acima pontuada é justificada, sobretudo, pela forma como alguns programas de pós-graduação em ensino de Ciências disponibilizam as informações sobre os trabalhos neles defendidos. Assim, tanto é possível encontrar informações desatualizadas sobre as dissertações e teses defendidas nos programas, a partir do acesso online aos seus sites; quanto pouca disponibilidade de versões alternativas àquela impressa. Com isso, fica evidente a necessidade de uma divulgação ampla desses documentos por parte de todos os programas de pós-graduação, de forma a possibilitar uma avaliação mais precisa do desenvolvimento da pesquisa em Ensino de Biologia.

Concordamos com Teixeira e Megid Neto (2011) quando pontuam que a realização de pesquisas dedicadas à análise do conjunto da produção acadêmica, nas mais diversas áreas de investigação, poderia contribuir para minimizar o problema da divulgação limitada e insuficiente da produção acadêmica desenvolvida no Brasil, buscando formas mais apropriadas para socializar, compatibilizar e integrar os conhecimentos gerados pelas pesquisas.

\section{b) Autores e orientadores}

Com base no currículo encontrado na Plataforma Lattes do Conselho Nacional de Desenvolvimento Científico e Tecnológico (CNPq), identificamos a formação inicial de 33 autores $(\approx 80 \%$ dos 41 autores) dos documentos analisados, restando oito autores para os quais essa informação não foi encontrada. Dentre os 33 autores que tiveram sua formação inicial identificada, verificamos que 13 autores $(\approx 39 \%$ ) possuem formação inicial na área de Ciências Biológicas; oito autores $(\approx 24 \%$ ) possuem formação inicial na área de Ciências, com habilitação em alguma de suas subáreas - Biologia, Física e Química; sete autores $(\approx 21 \%$ ) possuem formação inicial na área de Pedagogia, e cinco autores $(\approx 15 \%)$ possuem formação inicial em outras áreas não citadas anteriormente: Desenho e Artes Plásticas, Economia Doméstica, Medicina Veterinária, Odontologia e Química.

Analisando o perfil de formação inicial dos autores, é possível perceber que, dentre os oito autores com formação inicial em Ciências, seis autores $(\approx 18 \%)$ possuem habilitação em Biologia. Somando, a esse percentual, os autores que possuem sua formação inicial em Ciências Biológicas (13), temos uma estimativa de que, pelo menos, 57\% dos 33 autores possuem formação inicial diretamente relacionada com a área de Ciências Biológicas/Biologia. O fato de os autores apresentarem formação inicial relacionada à área de Ciências Biológicas/Biologia "parece ser um fator significativo para levar o discente a selecionar a subárea de Ensino de Biologia como campo de investigação no mestrado" (TEIXEIRA, 2008, p. 83).

Com relação ao perfil dos orientadores das dissertações, foi possível identificar um total de 26 orientadores, distribuídos entre professores orientadores e professores coorientadores. No conjunto de professores envolvidos com a orientação dos trabalhos, verificamos que seis exerceram apenas a função de orientadores, 11 exerceram apenas a função de coorientadores, e nove exerceram a função tanto de orientadores como de coorientadores.

Neste artigo, focaremos a análise no perfil dos professores que atuaram como orientadores principais das dissertações investigadas, por considerarmos a sua influência mais direta e decisiva no desenvolvimento dos trabalhos. O Quadro 1 apresenta informações referentes aos orientadores.

No total, 15 pesquisadores foram responsáveis pelas orientações das 41 dissertações analisadas. Deste total, quatro pesquisadores $(\approx 27 \%)$ orientaram um trabalho; cinco $(\approx 33 \%)$ orientaram dois trabalhos; dois $(\approx 13 \%)$ orientaram três trabalhos; dois $(\approx 13 \%$ ) orientaram 
seis trabalhos; um $(\approx 7 \%$ ) orientou quatro trabalhos; e um $(\approx 7 \%)$ orientou cinco trabalhos. A distribuição dos trabalhos por orientador mostrou que duas professoras podem ser consideradas as principais referências da pesquisa em ensino de Biologia no PPGEC/UFRPE. Cada uma delas reuniu seis orientações - este que foi o maior número de orientações por orientador estimado neste trabalho. Os demais estudos, 29, ficaram sob responsabilidade de 13 orientadores, revelando certa dispersão de orientações. Esta dispersão ocorre devido ao fato de professores que têm sua pesquisa focada em outra área específica, por vezes, assumirem orientações na área de Ensino de Biologia. Tal situação é justificável a partir da diversidade de objetos de pesquisa, que, muitas vezes, não se limitam ao conteúdo específico da Biologia.

Quadro 1. Orientadores das dissertações relacionadas ao ensino de Biologia defendidas no PPGEC/ UFRPE no período 2003-2009

\begin{tabular}{|c|c|c|c|c|}
\hline $\mathbf{N}^{\mathbf{o}}$ & Orientadores & Formação inicial & Área de maior titulação & Documentos \\
\hline 1 & AMARAL, E. M. R. & Engenharia Química & Educação & 2 \\
\hline 2 & AZEVEDO JÚNIOR, S. M. & Medicina Veterinária & Ecologia e Recursos Naturais & 2 \\
\hline 3 & BARBOSA, R. M. N. & Química & Educação Química & 2 \\
\hline 4 & BASTOS, H. F. B. N. & Física & Ensino de Física & 2 \\
\hline 5 & CAMPOS, A. F. & Química Industrial & Química & 1 \\
\hline 6 & CRUZ, MAOM & Ciências Biológicas & Psicologia & 2 \\
\hline 7 & FERREIRA, H. S. & $\begin{array}{l}\text { Engenharia e Ciências } \\
\text { de Materiais }\end{array}$ & $\begin{array}{l}\text { Ciências e Engenharia de } \\
\text { Materiais }\end{array}$ & 4 \\
\hline 8 & JÓFILI, Z. M. S. & Sociologia Política & Educação & 6 \\
\hline 9 & LEÃO, A. M. A. C & Medicina & Ciências/ Bioquímica & 6 \\
\hline 10 & LEÃO, M. B. C & Química & Tecnologia da Educação & 3 \\
\hline 11 & MENEZES, A. P. A. B. & Psicologia & Educação & 1 \\
\hline 12 & NOGUEIRA, R. A. & Matemática & Ciências Biológicas & 1 \\
\hline 13 & OLIVEIRA, M. M. & Pedagogia e Filosofia & Educação & 5 \\
\hline 14 & SILVA, R. M. A. & Pedagogia & Sociologia & 3 \\
\hline 15 & WILLADINO, L. & Ciências Biológicas & Ciências Biológicas & 1 \\
\hline
\end{tabular}

Fonte: elaborado pelas autoras. 
Informações obtidas com base na consulta ao currículo dos orientadores, disponível na Plataforma Lattes do CNPq, mostraram que a maior parte deles não possui formação inicial diretamente relacionada com as áreas de Ciências Biológicas/Biologia ou Ensino de Biologia. E nem, de forma mais abrangente, com a área de Educação. No entanto, percebemos que os dados relativos à área de maior titulação acadêmica dos orientadores parecem modificar o perfil de aproximação destes com a área de Ciências Biológicas/Biologia, de Ensino de Biologia, ou de Educação. Pois, $73 \%$ dos orientadores apresentam maior título em uma das áreas anteriormente citadas.

Finalizando as discussões relativas aos orientadores, concordamos com Teixeira (2008) quando pontua que os pesquisadores responsáveis pelas orientações das pesquisas em Ensino de Biologia estão vinculados ao campo mais amplo do Ensino de Ciências, e não, exclusivamente, ao campo do Ensino de Biologia. No caso do PPGEC/UFRPE, destacamos ainda, que os pesquisadores responsáveis pelas orientações das pesquisas em Ensino de Biologia estão também vinculados ao campo da Educação, além do Ensino de Ciências, e não exclusivamente ao Ensino de Biologia.

A forte presença do campo da Educação nas pesquisas em Ensino de Ciências, e, por consequência, no Ensino de Biologia, é pontuada por Cachapuz, Praia e Jorge (2004), quando afirmam que foi necessário à Educação em Ciências proceder a apropriações de saberes pertinentes a outras áreas disciplinares, sobretudo aquelas relativas à História e Filosofia da Ciência, Psicologia, Ciências da Educação e Sociologia da Ciência. Tal fato aproxima o Ensino de Ciências da área de Ciências Humanas e Aplicadas, justificando o vínculo de vários orientadores das dissertações sobre Ensino de Biologia com outras áreas do conhecimento que não o Ensino de Biologia.

No tocante ao sistema de orientação e coorientação, representativo ao longo do período em análise, constatamos que, do conjunto das 41 dissertações analisadas, 35 estudos $(\approx 85 \%)$ foram desenvolvidos em regime de coorientação. Ficando apenas seis estudos $(\approx 15 \%)$ orientados por um único pesquisador. O regime de coorientação é uma característica do PPGEC/ UFRPE, e, de acordo, com outras pesquisas correlatas à nossa, esse regime é uma estratégia pouco utilizada em programas de pós-graduação em Ensino de Ciências no Brasil (TEIXEIRA, 2008). No caso do PPGEC/UFRPE, o regime de coorientação foi adotado no período da constituição e consolidação do programa para promover a interação entre professores com formação na área específica e na área de educação. Facilitando, dessa forma, a articulação de aportes teóricos das diferentes áreas para a discussão dos problemas de pesquisa propostos.

\section{c) Nível de ensino}

Todos os níveis da educação formal - Ensino Infantil (EI), Ensino Fundamental (EF), Ensino Médio (EM) e Ensino Superior (ES) - foram contemplados nas dissertações analisadas. Assim, do conjunto analisado: dois estudos se dedicaram ao EI; vinte estudos se dedicaram ao EF; oito estudos se dedicaram ao EM, e cinco estudos se dedicaram ao ES. Foi analisado um estudo que se dedicou ao EF, EM e ES de forma articulada, e outros cinco estudos que se dedicaram ao ensino de Biologia de forma genérica, sem privilegiar um nível de ensino particular (Tabela 1). Podemos perceber, dessa forma, que a maioria das dissertações aborda um nível de ensino em particular. 
Silva, M. G.; Amaral, E. M. R.

Tabela 1. Nível de ensino privilegiado nas dissertações sobre Ensino de Biologia do PPGEC/UFRPE no período 2003-2009

Nível de Ensino

2003200420052006200720082009 Total

Ensino Infantil

Ensino Fundamental/Geral

Ensino Fundamental I

Ensino Fundamental II

Ensino Médio

Ensino Superior

Ensino Fundamental, Ensino Médio e Ensino Superior

Geral

Total

$\begin{array}{rrrrrrrr} & & & & & 1 & 1 & 2 \\ 1 & 4 & 4 & 3 & & & 2 & 14 \\ 1 & & 1 & 2 & 3 & 1 & & 8 \\ & 1 & 1 & & 1 & & 2 & 5 \\ & & & & 1 & & & 1 \\ 1 & 1 & 8 & & & 2 & 1 & 5 \\ 3 & 8 & & 5 & 5 & 5 & 7 & 41\end{array}$

Fonte: elaborado pelas autoras.

O nível de ensino com maior destaque nas dissertações analisadas foi o EF $(\approx 49 \%)$. Os trabalhos que investigaram problemáticas associadas a este nível de ensino se dividiram entre: aqueles que se dedicaram a uma abordagem mais genérica do EF (dois trabalhos); aqueles que se dedicaram a questões do Ensino Fundamental I (quatro trabalhos); e, ainda, aqueles que se dedicaram ao Ensino Fundamental II (14 trabalhos). Assim, a pesquisa sobre Ensino de Biologia desenvolvida no PPGEC/UFRPE durante o período analisado apresentou-se fortemente dedicada às particularidades do Ensino Fundamental II. Esta é uma característica marcante do PPGEC/UFRPE, uma vez que resultados de pesquisas sobre a produção acadêmica nacional em Ensino de Biologia (SLONGO; DELIZOICOV, 2006; TEIXEIRA; MEGID NETO, 2006) identificam o Ensino Médio e o Ensino Superior como níveis de ensino predominantes nos trabalhos da área. A predominância do Ensino Fundamental como foco nas dissertações analisadas pode ser justificada pelo fato de o Ensino de Ciências, nesse nível de ensino, ser historicamente um campo privilegiado de atuação de biólogos (TEIXEIRA, 2008).

O Ensino Médio é o segundo nível de ensino mais contemplado nas dissertações. Aproximadamente 19\% dos estudos se dedicam a este nível de ensino. A significativa presença de problemáticas relativas ao Ensino Médio, na pesquisa sobre Ensino de Biologia, não é uma característica particular do PPGEC/UFRPE. Assim, se justifica, sobretudo, pelo fato de ser neste nível de ensino que a Biologia aparece como uma disciplina escolar específica (MARANDINO; SELLES; FERREIRA, 2009). Outra justificativa é o fato de ser nesse nível de ensino que se busca aprofundar o conhecimento acerca dos conceitos abstratos da Biologia. E, com isso, surgem inúmeras dificuldades que, muitas vezes, são transformadas em problemas de pesquisa.

O foco no Ensino Superior apareceu em cerca de 12\% dos trabalhos analisados, o que representou um interesse modesto dos autores por este nível de ensino. Isso pode estar associado ao fato de muitos desses autores preferirem as problemáticas que envolvem o Ensino Fundamental e Médio, por serem professores em exercício nestes níveis de ensino. E, então, buscarem investigar problemáticas provenientes de suas próprias práticas. Essa forte ligação dos autores com as práticas que desenvolvem na Educação Básica contribui para que os mesmos não se interessem, pelo menos a princípio, em desenvolver pesquisas direcionadas 
ao Ensino Superior. Alves-Mazzotti (2001, p. 41) assinala, a esse respeito, que "muitos pesquisadores iniciantes, principalmente os alunos de mestrado, são levados a permanecer 'colados' em sua própria prática, dela derivando o seu problema de pesquisa e a ela buscando retornar com aplicações imediatas dos resultados obtidos". No entanto, vale salientar a importância da realização de estudos que apresentem envergadura teórica para a pesquisa em ensino de Ciências, especialmente no PPGEC/UFRPE, onde trabalhos desta natureza se configuram em uma lacuna do programa.

Por fim, o foco Ensino Infantil correspondeu a apenas 5\% dos estudos analisados. Essa característica demonstrou que são bastante limitados os estudos sobre o Ensino Infantil no PPGEC/UFRPE. Além de apontar uma necessidade de o programa desenvolver pesquisas voltadas para este nível de ensino. Pois, nele, também estão presentes os conteúdos biológicos, que não podem ser negligenciados.

\section{d) Focos temáticos}

Ao identificarmos os focos temáticos trabalhados nas dissertações analisadas, verificamos um aspecto importante: cada estudo envolveu problemáticas que possibilitaram a classificação em mais de um foco temático. Dessa forma, o indicador foco temático foi analisado a partir do foco temático principal e do foco temático secundário que cada estudo apresentou. É importante destacar, ainda, que os estudos tinham a possibilidade de apresentar as mais diversas combinações entre os focos principais e secundários. Podendo, desse modo, um único estudo apresentar dois focos principais e um secundário, por exemplo.

Diante do exposto, na apresentação dos dados, cada documento pôde estar associado a mais de um foco principal ou mais de um foco secundário, dependendo da forma como os autores abordaram as temáticas nos seus respectivos trabalhos. Esse mesmo procedimento foi adotado por Megid Neto (1999) e Teixeira (2008), visando facilitar o entendimento dos aspectos que este descritor revela. Assim, a partir dos procedimentos citados, o quadro 2 mostra os focos temáticos principais das dissertações analisadas neste estudo, além de seus respectivos títulos e ano de defesa.

Neste artigo, optamos por caracterizar os focos temáticos privilegiados nas dissertações analisadas de maneira geral, deixando, para publicações posteriores, as discussões relativas às problemáticas internas de cada foco temático.

Considerando os 13 focos temáticos sugeridos pelo CEDOC, verificamos que nove $(\approx 69 \%)$ desses focos foram alvos das pesquisas desenvolvidas sobre Ensino de Biologia no PPGEC/UFRPE, no período estudado. Apenas quatro focos temáticos $(\approx 31 \%$ ) não foram contemplados nas pesquisas investigadas, são eles: Organização da Instituição/Programa de Ensino Não-Escolar, Políticas Públicas, História do Ensino de Ciências e Filosofia da Ciência. As informações sobre os focos temáticos principais e secundários identificados nas 41 dissertações em Ensino de Biologia do PPGEC/UFRPE, no período investigado (2003-2009), estão reunidas na Tabela 2 .

Considerando apenas os focos temáticos primários, a pesquisa sobre Ensino de Biologia desenvolvida no PPGEC/UFRPE, no período investigado, apresentou como temáticas prioritárias: Conteúdo-Método; Recursos Didáticos, Características do Professor e Características do Aluno. Essas temáticas prioritárias também caracterizam a pesquisa nacional sobre o Ensino de Biologia, somadas a outras duas: Currículo-Programa e Formação de Professores (TEIXEIRA, 2008). 
Quadro 2. Focos temáticos principais das dissertações sobre ensino de Biologia defendidas no PPGEC/ UFRPE no período estudado (2003-2009)

\begin{tabular}{|c|c|c|c|}
\hline $\mathbf{N}^{\mathbf{o}}$ & Título da dissertação & $\begin{array}{c}\text { Ano } \\
\text { defesa }\end{array}$ & Foco temático principal \\
\hline 1 & $\begin{array}{l}\text { Diabetes mellitus em uma perspectiva de complexidade: } \\
\text { uma proposta de projeto transdisciplinar }\end{array}$ & 2006 & $\begin{array}{l}\text { 1. Formação de Professor } \\
\text { 2. Conteúdo e Método }\end{array}$ \\
\hline 2 & $\begin{array}{l}\text { Saberes disciplinares e experiências articulados em aulas } \\
\text { de biologia }\end{array}$ & 2007 & 1. Características do Professor \\
\hline 3 & $\begin{array}{l}\text { Síntese proteica: um estudo sobre a formação de } \\
\text { conceitos }\end{array}$ & 2009 & $\begin{array}{l}\text { 1. Conteúdo e Método } \\
\text { 2. Recursos Didáticos }\end{array}$ \\
\hline 4 & $\begin{array}{l}\text { As representações sociais dos alunos e professores da } \\
\text { escola municipal Karla Patrícia, Recife, PE, sobre o } \\
\text { manguezal }\end{array}$ & 2004 & $\begin{array}{l}\text { 1. Características do Professor } \\
\text { 2. Características do Aluno }\end{array}$ \\
\hline 5 & $\begin{array}{l}\text { A experimentação e a utilização de ambientes virtuais } \\
\text { de estudo na aprendizagem de conceitos sobre } \\
\text { clonagem vegetal }\end{array}$ & 2004 & 1. Conteúdo e Método \\
\hline 6 & $\begin{array}{l}\text { Investigando o desenvolvimento da concepção de } \\
\text { interdependência entre os elementos da biosfera, com } \\
\text { alunos do Ensino Fundamental I }\end{array}$ & 2005 & $\begin{array}{l}\text { 1. Conteúdo e Método } \\
\text { 2. Formação de Conceitos }\end{array}$ \\
\hline 7 & $\begin{array}{l}\text { Um paralelo entre conceitos alternativos e a construção } \\
\text { do conceito de hereditariedade }\end{array}$ & 2004 & $\begin{array}{l}\text { 1. Formação de Conceitos } \\
\text { 2. Características do Aluno }\end{array}$ \\
\hline 8 & $\begin{array}{l}\text { A transposição didática e os conteúdos de meio } \\
\text { ambiente e educação ambiental em áreas de manguezais } \\
\text { na } 4^{a} \text { série do Ensino Fundamental }\end{array}$ & 2009 & $\begin{array}{l}\text { 1. Currículos e Programas } \\
\text { 2. Conteúdo e Método }\end{array}$ \\
\hline 9 & $\begin{array}{l}\text { Educação ambiental e ensino de ciências: uma análise } \\
\text { de estratégias didáticas no nível fundamental }\end{array}$ & 2009 & 1. Conteúdo e Método \\
\hline 10 & $\begin{array}{l}\text { Formação continuada de professores de ciências na } \\
\text { rede pública estadual de Pernambuco }\end{array}$ & 2004 & 1. Formação de Professor \\
\hline
\end{tabular}

continua

No que se refere aos focos temáticos Currículo-Programa e Formação de Professores, percebemos que, embora eles não tenham sido eleitos como focos primários das pesquisas investigadas, eles marcaram, fortemente, essas pesquisas, em termos de foco secundário, sendo os dois mais representativos nesse nível de abordagem. Tal aspecto merece destaque, uma vez 
Quadro 2. continuação

\begin{tabular}{|c|c|c|c|}
\hline $\mathbf{N}^{\mathbf{o}}$ & Título da dissertação & $\begin{array}{c}\text { Ano } \\
\text { defesa }\end{array}$ & Foco temático principal \\
\hline 11 & $\begin{array}{l}\text { Aleitamento materno: representações sociais de } \\
\text { professores de ciências, profissionais de saúde e mães }\end{array}$ & 2006 & $\begin{array}{l}\text { 1. Características do Professor } \\
\text { 2. Características do Aluno }\end{array}$ \\
\hline 12 & $\begin{array}{l}\text { Ambientes de aprendizagem de ciências: a construção } \\
\text { de uma horta virtual de plantas medicinais }\end{array}$ & 2003 & $\begin{array}{l}\text { 1. Conteúdo e Método } \\
\text { 2. Recursos Didáticos }\end{array}$ \\
\hline 13 & $\begin{array}{l}\text { Formação de modelos mentais de alunos do Ensino } \\
\text { Médio por meio do uso de um software de genética }\end{array}$ & 2003 & $\begin{array}{l}\text { 1. Recursos Didáticos } \\
\text { 2. Características do Aluno }\end{array}$ \\
\hline 14 & $\begin{array}{l}\text { Investigando o desenvolvimento da concepção de } \\
\text { nanomundo no Ensino Fundamental }\end{array}$ & 2005 & $\begin{array}{l}\text { 1. Conteúdo e Método } \\
\text { 2. Formação de Conceitos }\end{array}$ \\
\hline 15 & $\begin{array}{l}\text { Formação continuada dos professores do ensino de } \\
\text { ciências naturais do centro de educação de jovens e } \\
\text { adultos }\end{array}$ & 2004 & 1. Formação de Professor \\
\hline 16 & $\begin{array}{l}\text { Softwares educacionais como auxiliares no ensino de } \\
\text { ciências: uma avaliação sob o enfoque da Teoria da } \\
\text { Flexibilidade Cognitiva (TFC) }\end{array}$ & 2004 & 1. Recursos Didáticos \\
\hline 17 & $\begin{array}{l}\text { Práticas docentes na educação infantil: o entrelace dos } \\
\text { saberes disciplinares e pedagógicos nas aulas de ciências } \\
\text { naturais }\end{array}$ & 2008 & $\begin{array}{l}\text { 1. Formação de Professores } \\
\text { 2. Características do Professor }\end{array}$ \\
\hline 18 & $\begin{array}{l}\text { Representações de professores de ciências sobre } \\
\text { formação continuada: o caso do encontro pedagógico } \\
\text { mensal da prefeitura da cidade do Recife }\end{array}$ & 2004 & 1. Características do Professor \\
\hline 19 & $\begin{array}{l}\text { Abordagem do ciclo do nitrogênio nas aulas de } \\
\text { ciências: o livro didático e as necessidades do professor }\end{array}$ & 2006 & 1. Recursos Didáticos \\
\hline 20 & $\begin{array}{l}\text { Concepções de professores e licenciandos em } \\
\text { ciências biológicas sobre os conceitos de bioética e } \\
\text { biossegurança no ensino com o uso de animais }\end{array}$ & 2007 & $\begin{array}{l}\text { 1. Características do Professor } \\
\text { 2. Características do Aluno }\end{array}$ \\
\hline
\end{tabular}

continua

que, das duas linhas de pesquisa do PPGEC/UFRPE, uma delas se dedica às investigações que envolvem a formação de professores e a construção de práticas docente no ensino de Ciências e Matemática. Tal fato justifica a forte presença do foco Formação de Professores na pesquisa em Ensino de Biologia desenvolvida no programa. No entanto, constatou-se a necessidade do 
Quadro 2. continuação

\begin{tabular}{|c|c|c|c|}
\hline $\mathbf{N}^{\mathbf{o}}$ & Título da dissertação & $\begin{array}{c}\text { Ano } \\
\text { defesa }\end{array}$ & Foco temático principal \\
\hline 21 & $\begin{array}{l}\text { O tema transversal orientação sexual nos PCN e a } \\
\text { atitude dos professores: convergentes ou divergentes? }\end{array}$ & 2009 & 1. Características do Professor \\
\hline 22 & $\begin{array}{l}\text { Ciclo celular: estudando a formação de conceitos no } \\
\text { Ensino Médio }\end{array}$ & 2007 & $\begin{array}{l}\text { 1. Conteúdo e Método } \\
\text { 2. Recursos Didáticos }\end{array}$ \\
\hline 23 & $\begin{array}{l}\text { Representações sociais de professores e licenciandos } \\
\text { em biologia sobre o bioma caatinga }\end{array}$ & 2009 & $\begin{array}{l}\text { 1. Características do Professor } \\
\text { 2. Características do Aluno }\end{array}$ \\
\hline 24 & $\begin{array}{l}\text { Implementando práticas pedagógicas em saúde bucal } \\
\text { no Ensino Fundamental I }\end{array}$ & 2005 & 1. Características do Professor \\
\hline 25 & $\begin{array}{l}\text { Uma investigação sobre concepções de alimentação } \\
\text { saudável de alunos do Ensino Fundamental }\end{array}$ & 2005 & $\begin{array}{l}\text { 1. Formação de Conceitos } \\
\text { 2. Características do Aluno }\end{array}$ \\
\hline 26 & $\begin{array}{l}\text { Alfabetização ecológica e formação de conceitos na } \\
\text { educação infantil por meio de atividades lúdicas }\end{array}$ & 2009 & $\begin{array}{l}\text { 1. Conteúdo e Método } \\
\text { 2. Recursos Didáticos }\end{array}$ \\
\hline 27 & $\begin{array}{l}\text { A mata atlântica nos livros didáticos de ciências } \\
\text { naturais e biologia }\end{array}$ & 2003 & 1. Recursos Didáticos \\
\hline 28 & $\begin{array}{l}\text { A interação do ciclo da experiência de Kelly com o } \\
\text { círculo hermenêutico-dialético, para a construção de } \\
\text { conceitos de biologia }\end{array}$ & 2006 & 1. Conteúdo e Método \\
\hline 29 & $\begin{array}{l}\text { O trabalho pedagógico dos professores do Ensino } \\
\text { Fundamental no ciclo II sobre educação ambiental, } \\
\text { Recife-PE }\end{array}$ & 2005 & 1. Características do Professor \\
\hline 30 & $\begin{array}{l}\text { Diagnóstico das dificuldades de articulação e } \\
\text { sobreposição dos conceitos básicos da genética } \\
\text { utilizando jogos didáticos }\end{array}$ & 2008 & 1. Recursos Didáticos \\
\hline 31 & $\begin{array}{l}\text { O projeto político-pedagógico e os princípios que } \\
\text { fundamentam a formação continuada dos professores } \\
\text { de ciências }\end{array}$ & 2009 & 1. Currículos e Programas \\
\hline
\end{tabular}

continua

desenvolvimento de trabalhos que se direcionem para as problemáticas concernentes à formação de professores, em termos de foco primário no PPGEC/UFRPE. Pois, a formação de professores corresponde a uma das linhas de pesquisa do programa. 
Quadro 2. continuação

\begin{tabular}{|c|c|c|c|}
\hline $\mathbf{N}^{\mathbf{o}}$ & Título da dissertação & $\begin{array}{c}\text { Ano } \\
\text { defesa }\end{array}$ & Foco temático principal \\
\hline 32 & $\begin{array}{l}\text { Educação ambiental e representações sociais: uma } \\
\text { análise transdisciplinar }\end{array}$ & 2005 & 1. Características dos alunos \\
\hline 33 & Um estudo sobre a evolução conceitual de respiração & 2007 & 1. Formação de Conceitos \\
\hline 34 & $\begin{array}{l}\text { Desenvolvimento sustentável nos livros didáticos de } \\
\text { biologia }\end{array}$ & 2005 & 1. Recursos Didáticos \\
\hline 35 & $\begin{array}{l}\text { Maré, mangue ou manguezal: um estudo de concepções } \\
\text { de estudantes no Ensino Fundamental }\end{array}$ & 2008 & $\begin{array}{l}\text { 1. Formação de Conceitos } \\
\text { 2. Características do Aluno }\end{array}$ \\
\hline 36 & $\begin{array}{l}\text { Etnia negra nos livros didáticos do Ensino } \\
\text { Fundamental: transposição didática e suas implicações } \\
\text { para o ensino das ciências }\end{array}$ & 2005 & 1. Recursos Didáticos \\
\hline 37 & $\begin{array}{l}\text { Saberes docentes, saberes indígenas: um estudo de caso } \\
\text { sobre o ensino de ciências entre o povo xukuru do } \\
\text { ororubá }\end{array}$ & 2008 & $\begin{array}{l}\text { 1. Conteúdo e Método } \\
\text { 2. Características do Professor }\end{array}$ \\
\hline 38 & $\begin{array}{l}\text { DNA X Transgênicos - um estudo das concepções de } \\
\text { licenciandos em biologia }\end{array}$ & 2004 & $\begin{array}{l}\text { 1. Formação de Professor } \\
\text { 2. Características do Aluno }\end{array}$ \\
\hline 39 & $\begin{array}{l}\text { As sequências de conteúdos em aulas de biologia: o uso } \\
\text { do livro didático }\end{array}$ & 2007 & 1. Recursos Didáticos \\
\hline 40 & O modelo webquest modificado & 2006 & 1. Recursos Didáticos \\
\hline 41 & $\begin{array}{l}\text { A contribuição das artes plásticas na aprendizagem de } \\
\text { conceitos científicos }\end{array}$ & 2008 & $\begin{array}{l}\text { 1. Conteúdo e Método } \\
\text { 2. Recursos Didáticos }\end{array}$ \\
\hline
\end{tabular}

Fonte: elaborado pelas autoras.

Outro aspecto a destacar é que alguns focos temáticos são contemplados apenas em nível de foco secundário, como é o caso da Organização da Escola e História da Ciência. Os trabalhos orientados para esses focos, em geral, estão relacionados a diferentes aspectos: o primeiro diz respeito à organização do macro/micro sistema educacional, e o segundo, com elementos históricos e filosóficos da educação em Ciências. Essas problemáticas ainda são incipientes no PPGEC/UFRPE, considerando as dissertações analisadas, não somente como questão principal, mas, também, como questão secundária. 
Tabela 2. Focos primários e secundários privilegiados nas dissertações sobre ensino de Biologia defendidas no PPGEC/UFRPE no período estudado (2003-2009)

\begin{tabular}{|c|c|c|c|c|}
\hline \multirow{2}{*}{ Foco temático } & \multicolumn{2}{|c|}{ Principal } & \multicolumn{2}{|c|}{ Secundário } \\
\hline & Quantidade & $\%$ & Quantidade & $\%$ \\
\hline Currículo e Programa & 2 & 4,8 & 10 & 24,3 \\
\hline Formação de professores & 5 & 12,1 & 8 & 19,5 \\
\hline Conteúdo e Método & 13 & 31,7 & 8 & 19,5 \\
\hline Recursos didáticos & 14 & 34,1 & 2 & 4,8 \\
\hline Formação de conceitos & 7 & 17 & 9 & 21,9 \\
\hline Características dos professores & 11 & 26,8 & 4 & 9,7 \\
\hline Características dos alunos & 10 & 24,3 & 6 & 14,6 \\
\hline História das Ciências & & & 2 & 4,8 \\
\hline Organização da escola & & & 1 & 2,4 \\
\hline Total de classificações & 62 & 150,8 & 50 & 121,5 \\
\hline
\end{tabular}

Fonte: elaborado pelas autoras.

Por fim, verificamos que quase $50 \%$ dos trabalhos analisados foram classificados com mais de um foco temático. Este aspecto foi encontrado com menor frequência em trabalhos que analisam a produção acadêmica no Ensino de Ciências e Biologia (MEGID NETO, 1999; TEIXEIRA, 2008). Esse dado pode ser uma indicação de que existam problemas relativos à estruturação das linhas de pesquisa no programa, por exemplo, uma definição pouco clara dos objetos investigados nessas linhas, e a existência de um número limitado de grupos de pesquisa constituídos no âmbito do programa.

\section{e) Gênero do trabalho acadêmico}

Para a análise das dissertações quanto ao descritor "Gênero do trabalho acadêmico", foram adotadas categorias propostas por Soares e Maciel (2000). Segundo essas autoras, quanto à natureza do texto, um documento pode ser classificado em Ensaio, Relato de Experiência ou Pesquisa. Segundo essa classificação, as 41 dissertações analisadas apresentaram natureza textual de Pesquisa, ou seja, são textos que analisam dados obtidos por meio de procedimentos cuidadosamente definidos e sistematizados, com o objetivo de investigar determinado objeto ou fenômeno (SOARES; MACIEL, 2000). Este resultado foi esperado, uma vez que o objetivo de um mestrado acadêmico é a formação para a pesquisa, não sendo adequados, portanto, textos de outras naturezas. Nesse sentido, evidenciamos o cuidado do programa com a produção de pesquisas e a formação de pesquisadores.

Os textos considerados como Pesquisa, segundo Soares e Maciel (2000) podem ser ainda classificados em três categorias gerais: Pesquisa Histórica, Pesquisa Descritivo-Explicativa e Pesquisa Experimental. Com base nessas categorias, verificamos que, das 41 dissertações analisadas, 39 estudos $(\approx 95 \%)$ correspondem à categoria Pesquisa Descritivo-Explicativa, e dois estudos $(\approx 5 \%)$ correspondem à Pesquisa Experimental. No conjunto das dissertações analisadas, nenhuma pesquisa foi classificada como Pesquisa Histórica.

As pesquisas classificadas como Pesquisa Descritivo-Explicativa, que representam a maioria das dissertações analisadas, de acordo com Soares e Maciel (2000) ainda podem ser or- 
ganizadas em seis subgêneros, são eles: Survey, Estudo de Caso, Estudo Comparativo, Análise de Documentos, Estudo Longitudinal e Estudo Transversal. A tabela 3 reúne as informações acerca dos subgêneros dos trabalhos classificados como Pesquisa Descritivo-Explicativa.

Considerando os subgêneros da Pesquisa Descritivo-Explicativa, as 39 dissertações classificadas neste gênero se organizaram da seguinte maneira: 22 trabalhos $(\approx 56 \%)$ foram caracterizados como Estudo de Caso; dez trabalhos $(\approx 25 \%)$ foram classificados como Estudos Comparativos; seis trabalhos $(\approx 15 \%)$ estão vinculados à categoria Análise de Documentos; e um trabalho $(\approx 3 \%)$ foi classificado como Estudo Longitudinal. Não houve trabalhos identificados como Survey ou Estudo Transversal. A partir dos dados, percebeu-se que a maior parte das pesquisas identificadas enquadrou-se no subgênero Estudo de Caso. Este caracterizado por investigar um fenômeno atual dentro do seu contexto de realidade, quando as fronteiras entre o fenômeno e o contexto não são claramente definidas, e no qual são utilizadas várias fontes de evidência (YIN, 2005).

Tabela 3. Classificação das dissertações sobre Ensino de Biologia defendidas no PPGEC/UFRPE (2003-2009), considerando os subgêneros da Pesquisa Descritivo-Explicativa

\begin{tabular}{|c|c|c|c|c|c|c|c|c|}
\hline \multirow{2}{*}{$\begin{array}{c}\text { Subcategorias da pesquisa } \\
\text { descritivo-explicativa }\end{array}$} & \multicolumn{7}{|c|}{$\mathbf{N}^{o}$ de documentos } & \multirow[b]{2}{*}{ Total } \\
\hline & 2003 & 2004 & 2005 & 2006 & 2007 & 2008 & 2009 & \\
\hline Estudo de caso & & 3 & 7 & 2 & 2 & 5 & 3 & $22(56,4 \%)$ \\
\hline Estudo comparativo & 1 & 3 & & 2 & 2 & & 2 & $10(25,6 \%)$ \\
\hline Análise de documentos & 1 & 1 & 1 & 1 & & & 2 & $6(15,4 \%)$ \\
\hline Estudo longitudinal & & & & & 1 & & & $1(2,6 \%)$ \\
\hline Total & 2 & 7 & 8 & 5 & 5 & 5 & 7 & $39(100 \%)$ \\
\hline
\end{tabular}

Fonte: elaborado pelas autoras.

Buscando compreender melhor a natureza dos trabalhos classificados como Estudo de Caso, fizemos uma análise das opções metodológicas que orientaram essas pesquisas. Esta análise foi realizada no sentido de verificar como esses estudos abordaram aspectos potencialmente significativos para o fenômeno ou fato investigado (SOARES; MACIEL, 2000). É importante ressaltar que cada documento analisado, e caracterizado, como Estudo de Caso utilizou mais de um instrumento/técnica de construção de dados para atingir seus objetivos.

Posto isso, constatamos que as técnicas e instrumentos de pesquisa utilizados nos trabalhos classificados como Estudo de caso, foram: observação de campo (12 estudos), questionário (oito estudos), videografia (oito estudos), entrevista (sete estudos), desenvolvimento de sequência didática (cinco estudos), análise de produção de textos, imagens e/ou esquemas (quatro estudos), gravação de áudio (três documentos), análise documental (três estudos), e registro fotográfico (dois estudos). Com isso, foi possível perceber que as pesquisas classificadas no subgênero Estudo de Caso realizam suas investigações a partir de uma grande diversidade de técnicas e instrumentos de pesquisa. Fato justificável, uma vez que o objetivo dos Estudos de Caso é estudar um dado fenômeno com profundidade, a partir de suas mais variadas facetas. 
De acordo com a Tabela 3, o segundo subgênero mais encontrado nos trabalhos analisados foi o Estudo Comparativo, com dez estudos. O Estudo Comparativo é caracterizado por buscar verificar a existência de relações causais, ou de associação, entre determinados fenômenos, no processo de ensino e aprendizagem de Biologia. Diferenciam-se da Pesquisa Experimental porque, enquanto nesta o pesquisador provoca a ocorrência dos fatos introduzindo variáveis no processo, no estudo comparativo-causal o pesquisador analisa aquilo que realmente ocorre sem a sua intervenção (SOARES; MACIEL, 2000).

Seguindo na caracterização da produção acadêmica do PPGEC/UFRPE, o terceiro subgênero mais encontrado foi a Análise de Documentos, que conta com seis trabalhos. As pesquisas classificadas como Análise de Documentos são caracterizadas por utilizarem o documento enquanto objeto de pesquisa (SOARES; MACIEL, 2000). O último subgênero mencionado na Tabela 2 foi o Estudo Longitudinal, caracterizado por pesquisas que acompanham o comportamento dos mesmos sujeitos ao longo do processo de ensino-aprendizagem de Biologia para identificar a sequência de estados ou de mudanças que ocorrem ao longo deste processo (SOARES; MACIEL, 2000). O número reduzido de trabalhos nos dois últimos subgêneros pode ser justificado por vários fatores, como, por exemplo, a demanda de maior tempo para estudos do tipo longitudinal, e o fato de o programa não possuir linha de pesquisa nas áreas de Currículo e Políticas Públicas, que supõem uma demanda de pesquisas sobre documentos.

Por fim, destacamos os estilos de textos encontrados ao longo de nossa análise. As dissertações analisadas apresentaram estrutura textual semelhante às sugeridas nas normas técnicas para trabalho científico propostas pela Associação Brasileira de Normas Técnicas (ABNT). Assim, os estudos apresentaram um estilo mais tradicional de texto, dividido em elementos pré-textuais, textuais e pós-textuais, seguindo as orientações da ABNT. No entanto, encontramos uma sutil variação na forma de apresentação dos resultados, elemento textual. Em alguns trabalhos, os resultados foram apresentados na forma de artigos científicos independentes e articulados. Com relação a essa pequena mudança no estilo dos textos, concordamos com Teixeira (2008) quando pontua que a formatação tradicional vem sofrendo transgressões ao longo do tempo, mas, ainda, continua sendo o estilo de texto privilegiado na pesquisa sobre Ensino de Biologia.

\section{Considerações finais}

Este artigo contribui para a divulgação e maior aproximação de dados regionais e nacionais sobre a produção acadêmica de programas de pós-graduação em Ensino de Ciências, neste caso, com trabalhos sobre o Ensino de Biologia. De maneira a suprir uma necessidade de caracterização das pesquisas desenvolvidas em programas instituídos recentemente e de regiões que estão fora do eixo Sudeste-Sul.

Assim, a produção acadêmica sobre o Ensino de Biologia do PPEGC/UFRPE, na forma de dissertações de Mestrado, no período de 2003 a 2009, apresentou uma dinâmica significativa. O que permitiu constatar a efetiva contribuição do referido programa para a pesquisa em Ensino de Biologia no estado de Pernambuco, e, por consequência, no Brasil. Neste trabalho, o conjunto de dissertações analisadas (41) foi caracterizado a partir de diferentes descritores que nos ajudaram a chegar às conclusões a seguir. 
Um número considerável de autores possui formação inicial na área de Ciências Biológicas, o que, muito provavelmente, leva esses pesquisadores a escolherem objetos de pesquisa relacionados de alguma forma com o ensino de Biologia. A grande maioria dos orientadores não apresenta formação inicial na área de Ciências Biológicas. Assim, estão vinculados à área de Ensino de Ciências, de maneira direta ou indireta, a partir da sua formação mais recente (doutorado ou pós-doutorado). Esse envolvimento de professores de diferentes áreas do conhecimento na pesquisa em Ensino de Ciências parece ser um marco na constituição da área. Esta que se constitui de pesquisadores tanto das áreas específicas como das áreas sociais e humanas, com interesses comuns em questões relativas à educação científica.

Referenciando-nos nas características da produção acadêmica em ensino de Biologia em nível nacional, foi possível perceber que as dissertações desenvolvidas no PPGEC/UFRPE tanto apresentam aproximações com aquela produção quanto especificidades em relação a ela.

Uma das características peculiares da produção do PPGEC/UFRPE é o regime de coorientação dos trabalhos. Este regime reflete uma necessidade inicial de o programa promover interação e articulação entre professores com formação em diversas áreas de conhecimento, para juntos orientarem trabalhos de pesquisa em Ensino de Ciências. Atualmente, com o crescimento no número de programas de pós-graduação em Ensino de Ciências, este quadro vem sofrendo mudanças, uma vez que podemos encontrar vários professores com doutorado em Ensino de Ciências, Educação em Ciências ou similar. Além da consolidação de muitos pesquisadores nessa área de pesquisa. Ainda há uma demanda considerável de pesquisadores com formação específica em Ensino de Ciências para atuação na formação de professores, tanto na pós-graduação como na graduação. Mas acreditamos que a tendência é de que essa demanda seja suprida em alguns anos.

Os níveis escolares privilegiados nas pesquisas foram o Ensino Fundamental, sobretudo nos seus anos finais, e o Ensino Médio. Acreditamos que essa tendência está relacionada com o fato de a maior parte dos autores ter experiência docente na Educação Básica, e buscar investigar problemas provenientes das suas próprias práticas. Esses resultados apontam para possibilidades de pesquisas futuras voltadas para níveis de ensino pouco explorados, por exemplo, o Ensino Superior e o Ensino Infantil. Além disso, são ressaltados os ambientes de educação não formal como uma possibilidade de futuros estudos, uma vez que as práticas docentes nesses espaços vêm se tornando mais presentes nas aulas de Biologia (MARANDINO; SELLES; FERREIRA, 2009).

As dissertações analisadas apresentaram uma considerável variedade temática, no entanto, podemos destacar os seguintes focos primários: Recursos Didáticos, Conteúdo-Método, Características do Professor e Características do Aluno. Tais temáticas estão associadas diretamente à prática docente, buscando resolver problemas que estão presentes nas salas de aula de Biologia, promovendo, assim, a melhoria de seu ensino. Com isso, propomos que estudos futuros possam avaliar o possível impacto que os trabalhos desenvolvidos tiveram ou têm na prática docente de professores, partindo do pressuposto de que essa prática tem mobilizado os professores nos processos de formação continuada. Além disso, outra possibilidade de estudo para o programa seria a realização de estudos de natureza mais teórica, que contribuem de igual forma para a melhoria do ensino de Ciências.

Finalmente, ressaltamos que a análise apresentada neste artigo, apesar de apresentar características específicas do PPGEC/UFRPE, que estão significativamente articuladas com 
o que vem sendo discutido na pesquisa em Ensino de Biologia em âmbito nacional, pode contribuir para o importante debate sobre as perspectivas para futuras pesquisas na área. Os trabalhos voltados, de algum modo, para o estado da arte da pesquisa em Ensino de Biologia ainda se apresentam de forma modesta no Brasil e, desse modo, são necessários novos estudos que busquem atualizar, otimizar, e rever descritores já consolidados. Nesse sentido, pode-se criar uma tradição de análise das pesquisas realizadas, buscando caracterizá-las com pertinência e clareza, possibilitando um conhecimento cada vez mais abrangente da pesquisa em Ensino de Biologia, o que poderá ser revertido em um maior impacto da pesquisa nos diferentes contextos educacionais.

\section{Referências}

ALVES-MAZZOTTTI, A. J. Relevância e aplicabilidade da pesquisa em educação. Cadernos de Pesquisa, São Paulo, n. 113, p. 39-50, jul. 2001. Disponível em: < http://www.scielo.br/ pdf/cp/n113/a02n113.pdf>. Acesso em: 10 fev. 2011.

CACHAPUZ, A.; PRAIA, J.; JORGE, M. Da educação em ciências às orientações para o ensino de ciências: um repensar epistemológico. Ciência $\&$ Educação, Bauru, v. 10, n. 3, p. 363-381, 2004. Disponível em: <http://www.scielo.br/pdf/ciedu/v10n3/05.pdf>. Acesso em: 15 abr. 2010.

MARANDINO, M.; SELLES, S. E.; FERREIRA, M. S. Ensino de biologia: histórias e práticas em diferentes espaços educativos. São Paulo: Cortez, 2009.

MEGID NETO, J. Tendências da pesquisa acadêmica sobre o ensino de ciências no nível fundamental. 1999. 365 f. Tese (Doutorado) - Faculdade de Educação, Universidade Estadual de Campinas, Campinas, 1999.

- Três décadas de pesquisas em educação em ciências: tendência de teses e

dissertações. In: NARDI, R. Pesquisa em ensino de ciências no Brasil: alguns recortes. São Paulo: Escrituras, 2007. p. 341-355.

- (Coord.). O ensino de ciências no Brasil: catálogo analítico de teses e dissertações, 1972-1995. Campinas: UNICAMP, 1998.

NARDI, R. A área de ensino de ciências no Brasil: fatores que determinam sua constituição e suas características segundo pesquisadores da área. In: Pesquisa em ensino de ciências no Brasil: alguns recortes. São Paulo: Escrituras, 2007. p. 257-412.

SLONGO, I. I. P. A produção acadêmica em ensino de biologia: um estudo a partir de teses e dissertações. 2004. 349 f. Tese (Doutorado) - Universidade Federal de Santa Catarina, Florianópolis, 2004.

SLONGO, I. I. P.; DELIZOICOV, D. Um panorama da produção acadêmica em ensino de biologia desenvolvida em programas nacionais de pós-graduação. Investigações em Ensino de Ciências, Porto Alegre, v. 11, n. 3, p. 323-341, 2006. 
SOARES, M. B.; MACIEL, F. (Org.). Alfabetização. Brasília: MEC, 2000. Disponível em: <http://www.dominiopublico.gov.br/download/texto/me000084.pdf >. Acesso em: 21 fev. 2015.

TEIXEIRA, P. M. M. Pesquisa em ensino de biologia no Brasil [1972-2004]: um estudo baseado em dissertações e teses. 2008. 418 f. Tese (Doutorado) - Faculdade de Educação, Universidade Estadual de Campinas, Campinas, 2008.

TEIXEIRA, P. M. M.; MEGID NETO, J. Investigando a pesquisa educacional: um estudo enfocando dissertações e teses sobre o ensino de biologia no Brasil. Investigações em Ensino de Ciências, Porto Alegre, v. 11, n. 2, p. 261-282, 2006.

Pós-graduação e pesquisa em ensino de biologia no Brasil: um estudo com base em dissertações e teses. Ciência \& Educação, Bauru, v. 17, n. 3, p. 559-578, 2011. Disponível em: <http://dx.doi.org/10.1590/S1516-73132011000300004>. Acesso em: 20 nov. 2011.

TEIXEIRA, P. M. M.; SANTOS, M. C. S. A pesquisa em ensino de biologia no Brasil: um recorte sobre as dissertações e teses que examinam recursos didáticos. Revista da SBEnBIO, Fortaleza, v. 1, p. 424-434, nov. 2010. 1 CD-ROM.

YIN, R. K. Estudo de caso: planejamento e métodos. 3. ed. Porto Alegre: Bookman, 2005. 